DISTRIBUTION STATEMENT A. Approved for public release; distribution is unlimited.

\title{
Finescale Water-Mass Variability from ARGO Profiling Floats
}

\author{
Eric Kunze \\ Applied Physics Lab, University of Washington \\ 1013 NE 40th \\ Seattle, WA 98105-6698 \\ phone: 206-221-2616 fax: 206-543-6785 \\ e-mail: kunze@apl.washington.edu
}

Award \#s: N00014-12-1-0336 and N00014-13-1-0484

\section{LONGTERM GOALS}

My longterm goals are understanding the processes responsible for stirring and mixing in the ocean in order to better parameterize their impacts on larger scales.

\section{OBJECTIVES}

To obtain a global assessment of mesoscale water-mass variability lengthscales and diffusivities, as well as density ratio statistics from the ARGO profiling float data set.

\section{APPROACH}

Mesoscale stirring depends on the eddy field, with eddies acting to stir tracers along isopycnals. In a simple stirring-length framework, horizontal diffusivities $K_{h}$ depend on rms eddy speed $U_{r m s}$ and stirring lengthscale $L$ as $K_{h}=U_{r m s} L$. One signature of eddy stirring in the presence of largescale gradients is water-mass (spice) variability along isopycnals. To estimate the eddy stirring length, ARGO profiling float data were transformed onto $\sigma_{\theta}$ density coordinates and salinity anomalies $S^{\prime}$ used as a proxy for water-mass variability. Salinity anomalies $S^{\prime}$ were combined with $2^{\circ} \times 2^{\circ}$ gradients on isopycnals $\left\langle S_{h}>\right.$ to determine lengthscales of stirring. The simplest lengthscale estimate, $L=$ $\left(<S^{, 2}>\right)^{1 / 2} /<S_{h}>$, is prone to overestimation in small mean gradients so an integral estimate of $L$ is obtained from $\left\langle S^{, 2}\right\rangle^{1 / 2}=\int<S_{h}(r)>d r$ where the integral runs from 0 to $L$. This stirring length will be combined with eddy horizontal kinetic energy estimates from the ECCO2 model to produce global estimates of lateral diffusivity to be compared with surface estimates based on satellite altimetry (Ferrari and Nikurashin 2010; Klocker and Abernathy 2014).

Similar methodology may be applied to isopycnal displacements $\xi$ to assess eddy APE variability though internal waves may dominate these statistics away from strong subinertial current systems.

Vertical (density) wavenumber spectra were computed for the water-mass anomalies in the profiles and these correlated as a function of lateral separation $\Delta r$ and temporal separation $\Delta t$. Also in the vertical, density ratio $R_{\rho}$ statistics have been mapped. 


\section{Report Documentation Page}

Form Approved

OMB No. 0704-0188

Public reporting burden for the collection of information is estimated to average 1 hour per response, including the time for reviewing instructions, searching existing data sources, gathering and maintaining the data needed, and completing and reviewing the collection of information. Send comments regarding this burden estimate or any other aspect of this collection of information,

including suggestions for reducing this burden, to Washington Headquarters Services, Directorate for Information Operations and Reports, 1215 Jefferson Davis Highway, Suite 1204, Arlington

VA 22202-4302. Respondents should be aware that notwithstanding any other provision of law, no person shall be subject to a penalty for failing to comply with a collection of information if it

does not display a currently valid OMB control number.

1. REPORT DATE

30 SEP 2014

4. TITLE AND SUBTITLE

Finescale Water-Mass Variability from ARGO Profiling Floats

6. $\operatorname{AUTHOR}(\mathrm{S})$

7. PERFORMING ORGANIZATION NAME(S) AND ADDRESS(ES)

University of Washington,Applied Physics Lab,1013 NE

40th,Seattle,WA,98105

9. SPONSORING/MONITORING AGENCY NAME(S) AND ADDRESS(ES)

12. DISTRIBUTION/AVAILABILITY STATEMENT

Approved for public release; distribution unlimited

13. SUPPLEMENTARY NOTES

14. ABSTRACT

15. SUBJECT TERMS

16. SECURITY CLASSIFICATION OF:

a. REPORT

unclassified b. ABSTRACT

unclassified c. THIS PAGE

unclassified
17. LIMITATION OF ABSTRACT

Same as

Report (SAR)
3. DATES COVERED

00-00-2014 to 00-00-2014

5a. CONTRACT NUMBER

5b. GRANT NUMBER

5c. PROGRAM ELEMENT NUMBER

5d. PROJECT NUMBER

5e. TASK NUMBER

5f. WORK UNIT NUMBER

8. PERFORMING ORGANIZATION REPORT NUMBER

10. SPONSOR/MONITOR'S ACRONYM(S)

11. SPONSOR/MONITOR'S REPORT $\operatorname{NUMBER}(\mathrm{S})$ 
If time permits, we will search the data for outliers in $T, S$ and stratification $N^{2}$ to map vortices analogous to Meddies. In the Indian, these might include Reddies from the Red Sea in the Arabian Sea (e.g., Shapiro and Meshchankov 1991) and vortices generated by flow of the Antarctic Circumpolar Current past the Kerguelen Plateau (D’Asaro 1988).

\section{WORK COMPLETED}

The global ARGO profiling float data set through 2012 has been downloaded from its archive and catalogued. Coherence analysis is complete. Postdoctoral researcher Dr. Cimmaron Wortham, who arrived in September 2013, has nearly completed lengthscale analysis and begun work on figures for at least two anticipated manuscripts.

\section{RESULTS}

The coherence of water-mass anomalies extends results of Ferrari and Polzin (2005) in the eastern North Atlantic, that coherence falls to zero at the smallest temporal and horizonal separations resolved (1 day, $5 \mathrm{~km}$ ) almost everywhere in the ocean, illustrating that TS properties are not smooth anywhere.

On the $\sigma_{\theta}=27.29(<z>=832 \mathrm{~m}$ ) surface (Fig. 1), stirring lengthscales $L$ show global patterns with $L$ of $\mathrm{O}(100-1000 \mathrm{~km})$. Longer stirring lengthscales are concentrated toward the west between $20-50^{\circ}$, as well as along the equatorial Pacific, south of the equator in the Atlantic and Indian but patterns vary with depth. Shorter lengthscales of $100 \mathrm{~km}$ are found in the subtropics and poleward of $60^{\circ} \mathrm{S}$ around Antarctica. Overall, larger lengthscales are associated with stronger mean currents and their associated eddy fields.

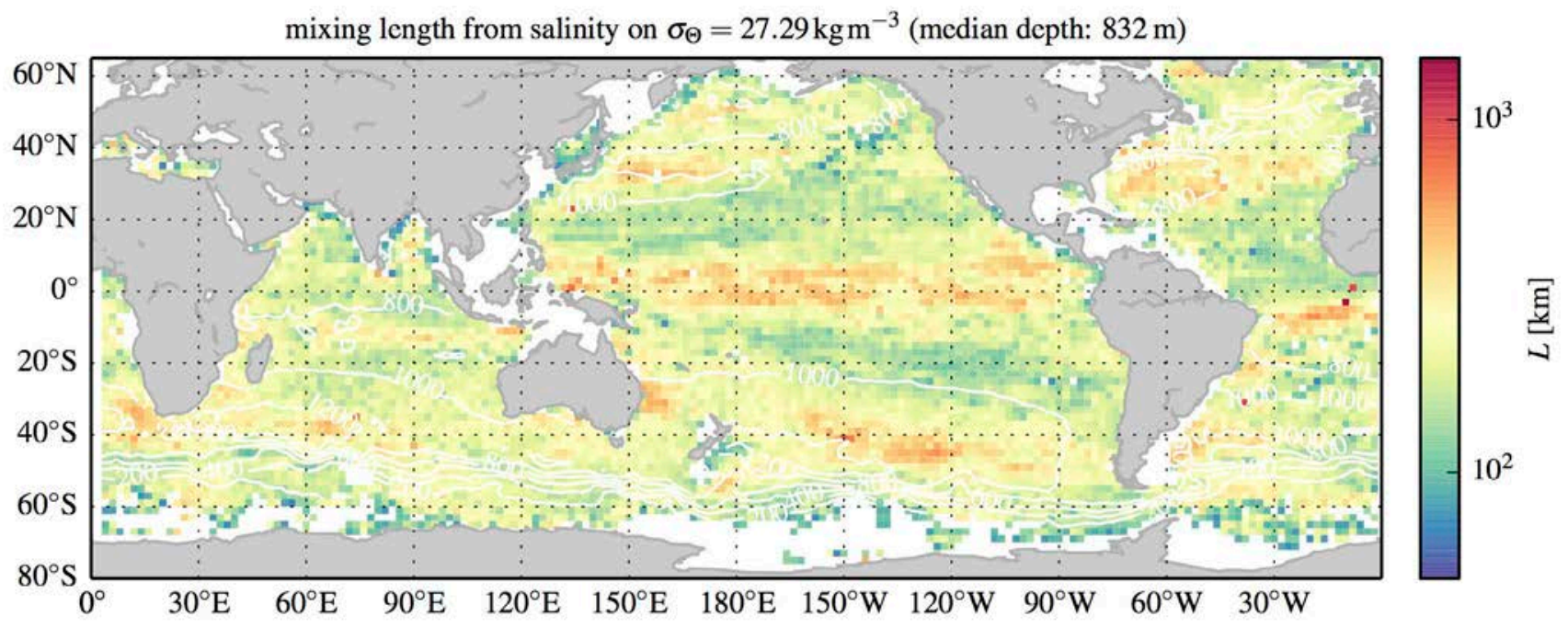

Figure 1: Stirring lengthscales $L$ in $2^{\circ} \times 2^{\circ}$ squares based on rms salinity anomalies $S$ ' on the $\sigma_{\theta}=$ $27.29\left(<_{\mathrm{z}}>=832 \mathrm{~m}\right)$ surface. Color shows lengthscale and white contours mean isopycnal depths $<\mathrm{z}>$ in meters.

Meridional sections show strong vertical and zonal coherence of lengthscale statistics (Fig. 2). For example, a local minimum in lengthscale at $40^{\circ} \mathrm{N}$ extends across the Pacific fro $170^{\circ} \mathrm{E}$ to $140^{\circ} \mathrm{W}$, just north of the Kuroshio extension. The horizontal structure in lengthscale $L$ indicates that eddy stirring 
lengths are not simply dependent on eddy diameter, which generally decreases monotically with latitude, but also depend on eddy/mean current characteristics and interactions.
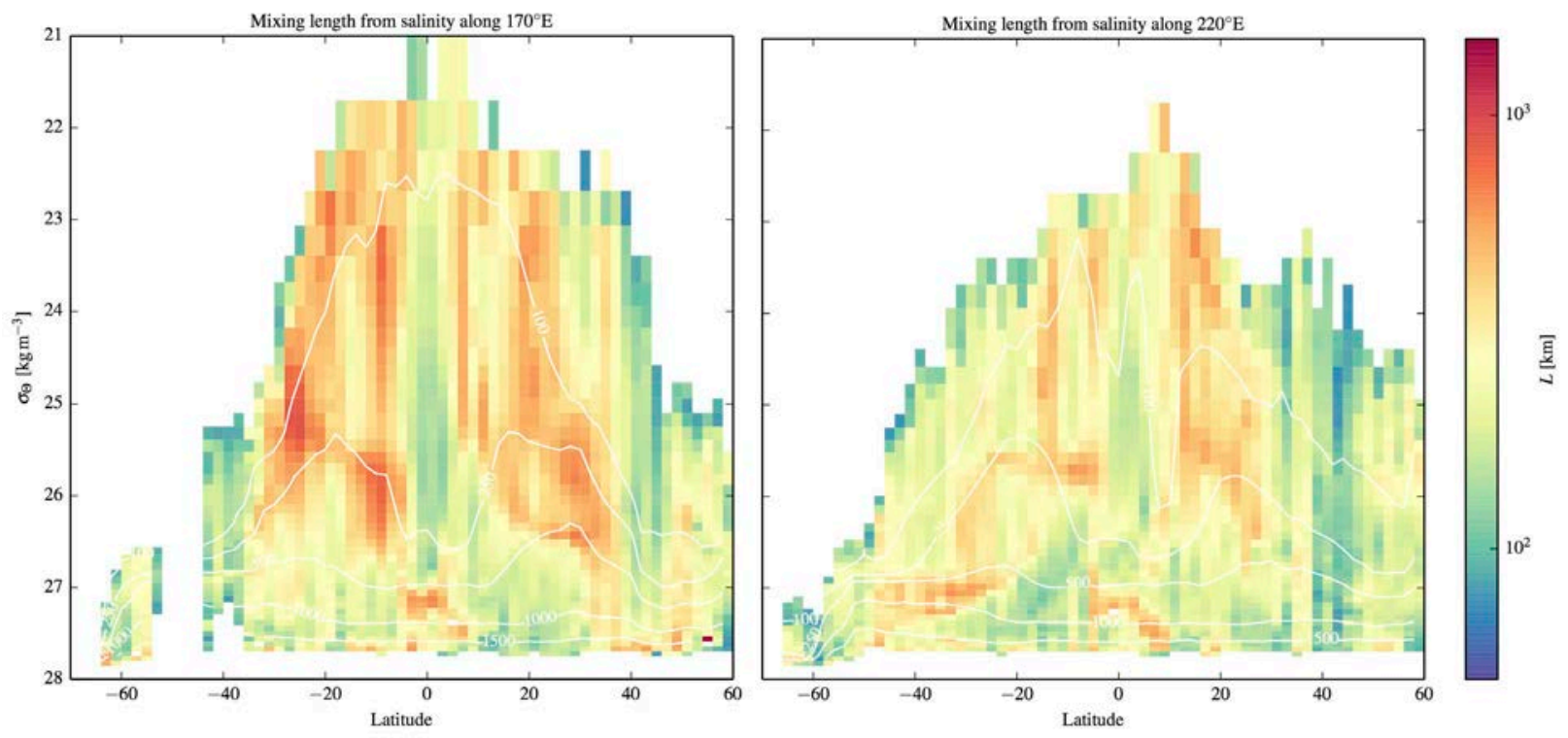

Figure 2: Meridional sections of isopycnal stirring lengthscales $L$ as a function of $\sigma_{\theta}$ and latitude in the western (left) and eastern (right) Pacific. Color shows lengthscale and white contours average isopycnal depths $<\mathrm{z}>$ in meters.

\section{IMPACT/APPLICATIONS}

Global mapping of water properties has typically focussed on smoothed basin-scale fields (e.g., You 2002). However, the dramatic increase in available data afforded by the ARGO float array allows mesoscale variances and lengthscales to be examined as well. Water-mass variability on isopycnals provides signatures of stirring that will impact isopycnal mixing, double-diffisive processes and acoustics.

\section{RELATED PROJECTS}

This project is examining the global distribution of mesoscale water-mass variability, arising from advection by currents and stirring by eddies, to better characterize lateral stirring on $\mathrm{O}(100 \mathrm{~km})$ lengthscales. This variability represents the low-wavenumber source for the submesoscale being studied under ONR's Lateral Mixing DRI. For the Lateral Mixing DRI, I have synthesized data from towyo measurements collected by Jody Klymak, Craig Lee, Miles Sundermeyer and myself, as well as autonomous measurements collected by Lou Goodman, during the summer 2010 field campaign in the Sargasso Sea, to produce a spectrum for water-mass variability on isopycnals over horizontal wavelengths of 0.03-30 km (Kunze et al. 2014). The submesoscale band represents the forward cascade of variance on lengthscales smaller than the Rossby radiation of deformation so the two lines of research complement each other. 


\section{REFERENCES}

D’Asaro, E.A., 1988: Geneation of submesoscale vortices - A new mechanism. J. Geophys. Res., 93, 6685-6693.

Ferrari, R., and K.L. Polzin, 2005: Finescale structure of the T-S relation in the eastern North Atlantic. J. Phys. Oceanogr., 25, 1437-1454.

Ferrari, R., and M. Nikurashin, 2010: Suppression of eddy diffusivity across jets in the Southern Ocean. J. Phys. Oceanogr., 40, 1501-1519.

Klocker, A., and R. Abernathy, 2014: Global patterns of mesosclae eddy properties and diffusivities. J. Phys. Oceanogr., 44, 1030-1046.

Kunze, E., J.M. Klymak, R.-C. Lien, R. Ferrari, C.M. Lee, M.A. Sundermeyer and L. Goodman, 2014: Submesoscale water-mass spectra in the Sargasso Sea. J. Phys. Oceanogr., submitted.

Shapiro, G.I, and S.L. Meshchanov, 1991: Distribution and spreading of Red Sea Water and salt lens formation in the northwest Indian Ocean. Deep-Sea Res., 38, 21-34.

You, Y., 2002: A global ocean climatological atlas of the Turner angle: Implications for doublediffusion and water-mass structure. Deep-Sea Res. I, 49, 2075-2093. 